\title{
A EDUCAÇÃO AMBIENTAL, ESTUDO E INTERVENÇÃO DO MEIO
}

\author{
Maria Gizelda de Oliveira Tavares \\ Professora Adjunto da Universidade Federal de Goiás (UFG) \\ Eliecilia de Fátima Martins \\ Professora da Universidade Salgado de Oliveira (UNIVERSO) \\ Gislene Margaret Avelar Guimarães
}

Aluna de pós graduação da Faculdade de Educação da Universidade Federal de Goiás(UFG)

\section{INTRODUÇÃO}

A Educação Ambiental, há poucas décadas discutida no Brasil, vem assumindo novas dimensões a cada ano, principalmente pela urgência de reversão do quadro de deterioração ambiental em que vivemos, efetivando práticas de desenvolvimento sustentado e melhor qualidade de vida para todos e aperfeiçoando sistemas de códigos que orientam a nossa relação com o meio natural. Trata-se de compreender e buscar novos padrões, construídos coletivamente, de relação da sociedade com o meio natural.

No campo escolar a Educação Ambiental está presente nas Propostas Curriculares do Ensino Fundamental de 21 estados brasileiros ${ }^{1}$, incluindo o Estado de Goiás, cuja Proposta Curricular de Ciências tem como eixo norteador o meio ambiente ${ }^{6}$ e está presente também nos Parâmetros Curriculares Nacionais (PCNs) ${ }^{4}$ como tema transversal, perpassando todas as disciplinas do currículo. Pressupõe a discussão de questões éticas, ecológicas, políticas, econômicas, sociais, legislativas e culturais ${ }^{3}$

Consideramos que a participação de alunos do terceiro grau em projetos de Educação Ambiental que os aproxime da realidade escolar durante a formação acadêmica, permite ao graduando a percepção da diversidade sócio-ambiental e da indissociabilidade entre a teoria e a prática referentes à educação ambiental, possibilitando, ao mesmo tempo, a construção de uma práxis que contribua para o desenvolvimento relações de equilíbrio entre natureza/sociedade humana.

Dessa forma, foi desenvolvida uma proposta pedagógica com alunos do curso de Química da Universidade Federal de Goiás, na qual há estudo e analise da realidade de um determinado ambiente, elaboração de uma proposta de intervenção e execução da mesma.

O trabalho educativo aqui descrito se inspira na Pedagogia de Paulo Freire (1982), cuja estratégia epistemológica principal é a interação dialógica dos sujeitos entre si e com a realidade. Representa uma tentativa de trazer, junto às mudanças de postura em relação aos ambientes, as imagens e representações que os indivíduos constróem de uma realidade e de um lugar, bem como a forma como interpretam suas histórias e vivências nesse lugar. Deste modo, estamos levando em conta não uma única realidade, totalizante e absoluta, mas as diversas configurações que assume o imaginário dos sujeitos. 


\section{OBJETIVOS}

? Avaliar uma modalidade de formação em educação ambiental

? Proporcionar condições para que os alunos de Química Ambiental possam vivenciar os problemas ambientais em escolas de ensino fundamental e propor melhoramentos ou mesmo soluções neste âmbito

? Possibilitar aos alunos de Química Ambiental, condições efetivas de redimensionamento da relação teoria prática

? Contribuir com subsídios teóricos e práticos para o desenvolvimento da educação ambiental nas escolas da Rede Pública de Goiânia

\section{O campo de estudo}

Na periferia as dificuldades são maiores, a população sofre por falta de infra-estrutura básica. Com o aumento populacional, cidades crescem desordenadamente, crescem também os riscos de epidemias e de doenças infecto-contagiosas. A fome, o desemprego, a falta de habitação, de saneamento básico, de lazer e de escola, a deficiência no transporte coletivo e a marginalidade são problemas que afligem a população periférica aos centros urbanos.

Neste contexto está a Região Noroeste de Goiânia, considerada como bolsão de pobreza da cidade, onde a população sofre com os problemas gerados pela falta de recursos econômicos, na maioria das vezes em situação de miséria. Nessa região, pode-se ver um mundo em que se evidenciam problemas ambientais que envolvem as inter-relações e interdependência dos diversos elementos de constituição e manutenção da vida.

Em termos de educação ambiental, percebe-se a necessidade de um trabalho vinculado aos princípios da dignidade do ser humano, da participação, da responsabilidade, da solidariedade e da qualidade de vida ${ }^{8}$

Entendendo a escola como um lugar onde se dá parte do processo de socialização da criança - o que nela se faz, se diz e se valoriza, significa para os pequenos, um exemplo daquilo que a sociedade quer e aprova - ela passa a ser um dos instrumentos fundamentais para o desenvolvimento da Educação Ambiental na Região Noroeste de Goiânia.

\section{Fundamentos metodológicos}

O envolvimento e a participação coletiva dos indivíduos na busca de soluções para diversos problemas ambientais com os quais deparamos, é um dos aspectos fundamentais dos trabalhos educativos, podendo se constituírem numa oportunidade para o desenvolvimento de habilidades relacionadas à participação política e ao processo de construção da cidadania. 
Uma das conseqüências práticas desta concepção é a busca de procedimentos didáticos que contribuam para o fazer pedagógico do educador ambiental. A prática de ensino sustentada por simples processos de transmissão/assimilação de conhecimentos não é suficiente ou adequada para a educação ambiental. Por outro lado, a formação de imagens mentais, representações, conhecimentos, expectativas e julgamentos são fundamentais para compreender as relações com o meio ambiente e, em decorrência, para instituir ações diferenciadas sobre ele (Rio, 1996). Nesse sentido, para superar a fragmentação do conhecimento estuda-se uma realidade em sua multiplicidade de aspectos, onde saberes das diversas áreas estão concretizados.

Logo, o envolvimento mais amplo possível do educando em atividades cognitivas ou intelectuais, o posicionamento frente a questões de valores ou participação coletiva e direcionada para soluções de problemas da comunidade são princípios metodológicos da Educação Ambiental, que deve ser contextualizada no tempo e no espaço, valorizando o coletivo, a diversidade e o confronto das diferenças ${ }^{5}$.

Assumir estes princípios significa, no plano operacional, percorrer uma 'trilha pedagógica', através da qual alunos e professores são levados a flagrarem-se com suas imagens do lugar de caráter figurativo e simbólico, passando, em seguida, à geração de informações sobre esse ambiente, processo, desta vez, eminentemente cognitivo, até chegar à escolha de alternativas e, finalmente, de intervenção.

Quando o objetivo é a mudança de postura dos indivíduos (no caso os alunos de Química) é fundamental que a metodologia utilizada proporcione condições para estabelecer um contato com o problema num plano mais significativo, pois a relação dos indivíduos com o ambiente expressa suas crenças, valores e representações, tanto as individuais, relacionadas com as suas histórias pessoais, quanto as coletivas, construídas no grupo social e, no âmbito pedagógico, expressa também o conhecimento e o nível de informação sobre as questões em estudo.

Através dos levantamentos, pesquisas e depoimentos realizados no estudo do meio, vem à tona uma realidade oculta, cuja reflexão e análise auxilia no desenvolvimento de uma consciência social e percepção de intervenções possíveis. Para apreendermos a realidade, para termos a sua essência, temos que desvendá-la, entender a teia das relações naturais e sociais que estão por trás do aparente e que o explicam. Temos que estudar essa realidade, decifra-la. Se não usarmos uma metodologia adequada não emergirá essa essência. Ficaremos no aparente, no fenômeno ${ }^{7}$.

Em uma perspectiva política esta concepção tem como objetivo que o sujeito se constitua como cidadão, consciente, crítico e atuante na busca de uma sociedade justa e democrática e ambientalmente saudável. É uma prática de ensino que permite ao aluno perceber-se parte da complexidade da realidade social, política e econômica de um espaço. Questiona os conteúdos tradicionalmente transmitidos na 
universidade. É um método de trabalho que tem como ponto de partida e de chegada o real e o vivido, pensado e refletido.

\section{METODOLOGIA}

O trabalho contou com a participação de 33 alunos do último ano do curso de Química, matriculados na disciplina Química Ambiental. Considerando os fundamentos metodológicos o trabalho se constituiu de cinco fases, descritas a seguir.

\section{? Levantamento das escolas}

A idéia inicial era que o trabalho abrangesse escolas municipais de todas as regiões de Goiânia. Porém, por intermédio da diretora de uma das escolas, realizou-se um encontro entre as professoras coordenadoras da proposta ora apresentada e um grupo de pessoas que constituem um Fórum de Debates dos Problemas da Região Noroeste de Goiânia, bem como representantes de várias escolas dessa região. Percebeu-se então, a importância de se fazer um elo entre os trabalhos de intervenção desenvolvidos pelo grupo na região e a proposta de educação ambiental apresentada, o que resultaria em uma ação mais efetiva e abrangente.

Em seguida, foram realizadas visitas às escolas com o objetivo de apresentar a proposta de Educação Ambiental e conhecer o projeto político pedagógico das mesmas, discutindo-se a consonância entre ambos. Desta forma, as escolas (totalizando oito) foram concentradas na Região Noroeste de Goiânia.

\section{? Contato e conhecimento do campo de estudo pelos alunos de Química}

$\mathrm{Na}$ seqüência, os universitários, divididos em grupos, visitaram as escolas, acompanhados pelas professoras orientadoras. Nessa ocasião, ouviram do Diretor, do Coordenador e dos Professores, as expectativas e os aspectos que deveriam ser desenvolvidos na educação ambiental, de acordo com as necessidades de cada escola.

A partir daí, cada grupo realizou um estudo das relações que a escola, sob sua responsabilidade, estabelecia com o contexto ambiental no qual ela estava inserida, aproximando-se então de cada realidade a ser trabalhada. Nesse sentido, também foram elaborados e aplicados questionários aos moradores, buscando definir o perfil da comunidade local.

\section{? Observação da região nos seus múltiplos aspectos ambientais}

No trabalho de observação do ambiente, foram avaliados aspectos como recursos hídricos, sistema de tratamento de água e esgoto, pavimentação, arborização, área de lazer, tipo de solo, reservas ecológicas, 
indústrias próximas (e o impacto ambiental dessas indústrias). Ao analisar esses aspectos, foram identificados problemas de responsabilidade individual como: pichações, depósito de lixo em locais não apropriados, despejo de esgoto doméstico em vias públicas e em corpos d'água, destruição de reserva ecológica, dentre outros, e de responsabilidade do poder público como: transporte coletivo insuficiente, falta de pavimentação e saneamento básico, com a formação de valas nas ruas, falta de segurança policial, falta de espaços de lazer, infra-estrutura precária. No âmbito escolar, foram identificados problemas como: depredações de carteiras, de banheiros e de equipamentos, falta de higiene pessoal(alunos) e da escola, lanche insuficiente, violência, dentre outros.

A observação desse meio por si só não é suficiente para entender uma realidade, mas é indispensável para que as questões sejam formuladas e respostas sejam buscadas. A partir de então, os estudantes, através da socialização dos grupos, fizeram tentativas de compreender a vida cotidiana da comunidade escolar em seus múltiplos aspectos ambientais.

Nos momentos de (re)conhecimento e análise da realidade da região Noroeste, foram buscados os diferentes saberes, as experiências, as expectativas e os problemas existentes, na tentativa de estabelecer um vínculo entre essa realidade e a realidade do aluno de Química na perspectiva de uma sensibilização que possibilite a transcendência do conhecimento.

\section{? $\quad$ Planejamento}

Em função dos problemas diagnosticados a partir do (re)conhecimento do meio, das necessidades da escola e da comunidade local, foi possível que cada aluno fizesse a leitura do meio ambiente, leitura essa pautada na historicidade de cada um, para então, a partir da socialização, chegar a um entendimento do grupo sobre as diretrizes do trabalho de educação ambiental. Passaram então as discussões sobre:

\section{? O que a escola precisa? \\ ? O que podemos fazer? \\ ? Como vamos fazer?}

O levantamento preliminar, as discussões em torno do local e do tema, as reflexões, a necessidade do comportamento ético, da segurança em relação aos fundamentos teóricos, fundamentaram o diálogo dos grupos.

Tal fundamentação contribuiu para o estabelecimento dos objetivos específicos do processo de Educação Ambiental, no planejamento das ações pedagógicas, realizado em conjunto com o corpo docente das escolas, buscando atender aos interesses e necessidades locais. Dessa forma, o trabalho organizacional passou a ser uma das garantias para um desempenho satisfatório das ações desenvolvidas. 
Segundo Guimarães (1995) ${ }^{2}$ na execução do plano de ação, o educando elabora uma nova forma de entendimento da prática social, na qual atuará conforme sua compreensão do meio, então modificada pelo conhecimento do mesmo.

Em consonância com esse plano de ação, cada grupo de alunos de Química desenvolveu as seguintes atividades nas escolas:

\begin{tabular}{|c|c|c|}
\hline $\begin{array}{c}\text { Escola } \\
\text { Municipal }\end{array}$ & Descrição do trabalho & Idade dos alunos \\
\hline $\begin{array}{lr}\text { Bairro } & \text { da } \\
\text { Vitória } & \text { Área } \\
\text { III }\end{array}$ & $\begin{array}{ll}? & \text { Sensibilização dos alunos sobre os problemas locais referentes ao lixo e ao } \\
& \text { desmatamento (elaboração dos dez mandamentos para preservação da natureza) } \\
? & \text { Oficina de reciclagem de lixo } \\
? & \text { Lanche comunitário para os alunos } \\
? & \text { Realização da coleta seletiva de lixo após o lanche e a oficina } \\
? & \text { Plantio de mudas na escola com os alunos e professores }\end{array}$ & $\begin{array}{c}5-7 \\
\text { anos }\end{array}$ \\
\hline $\begin{array}{l}\text { Bernardo } \\
\text { Elis }\end{array}$ & $\begin{array}{ll}\text { ? } & \text { Criação de acervo com textos específicos de meio ambiente, Mesa redonda com } \\
& \text { os professores, direção e coordenação da escola } \\
? & \text { Palestra para os alunos de como fazer coleta seletiva e reutilização de materiais }\end{array}$ & 7-14 anos \\
\hline $\begin{array}{ll}\text { Maria da } \\
\text { Terra }\end{array}$ & $\begin{array}{ll}? & \text { Palestra para os alunos de como fazer coleta seletiva e reutilização de materiais } \\
? & \text { Palestra sobre higiene pessoal }\end{array}$ & $5-8$ anos \\
\hline $\begin{array}{l}\text { Marco } \\
\text { Antônio Dias } \\
\text { Batista }\end{array}$ & $\begin{array}{ll}\text { ? } & \text { Criação de acervo com textos específicos de meio ambiente, Mesa redonda com } \\
& \text { os professores, direção e coordenação da escola } \\
? & \text { Palestra para os alunos de como fazer coleta seletiva e reutilização de materiais }\end{array}$ & $5-8$ anos \\
\hline Nadal Sfredo & $\begin{array}{ll}? & \text { Filme sobre higiene pessoal } \\
? & \text { Apresentação de teatro de fantoches } \\
? & \text { Palestras sobre lixo e higiene pessoal } \\
? & \text { Concurso de desenho sobre o meio ambiente }\end{array}$ & $5-8$ anos \\
\hline $\begin{array}{l}\text { Nova } \\
\text { Conquista }\end{array}$ & $\begin{array}{ll}\text { ? } & \text { Apresentação de teatro de fantoches } \\
? & \text { Palestras sobre lixo e reciclagem }\end{array}$ & $5-8$ anos \\
\hline $\begin{array}{l}\text { Professor } \\
\text { Paulo Freire }\end{array}$ & $\begin{array}{ll}? & \text { Oficina de artes, usando o tema lixo } \\
? & \text { Teatro com fantoches } \\
? & \text { Recreação } \\
? & \text { Lanche-educativo } \\
? & \text { Coleta seletiva do lixo com os alunos. }\end{array}$ & 6-14 anos \\
\hline $\begin{array}{l}\text { Stephane } \\
\text { Alves Bispo * }\end{array}$ & --- & --- \\
\hline
\end{tabular}

*Não permaneceu no projeto, uma vez que, apesar do interesse inicial da escola, posteriormente tal interesse não se manteve. 


\section{RESULTADOS OBSERVADOS}

Apesar das dificuldades manifestadas pelos alunos antes de iniciar o projeto, por considerarem a região muito perigosa e de difícil acesso, além da expectativa sobre a extensão do trabalho e a insegurança em relação à abordagem proposta na Educação Ambiental, foi gratificante observar, ao final deste trabalho experimental, que eles se sentiram úteis e ao mesmo tempo perceberam que a visão que tinham da Região Noroeste foi qualitativamente alterada. Lá encontraram pessoas humildes, marginalizadas, a maioria com um baixo grau de escolarização, mas, dispostas e com vontade de melhorar sua qualidade de vida.

A partir do relato dos alunos, destaca-se alguns aspectos em relações aos quais esses se mostraram perplexos e sensibilizados o que indica uma ampliação de sua de visão de mundo e dos problemas ambientais.

\section{? Infra estrutura da escola e da região}

São críticas às condições ambientais de algumas das escolas, apontadas pelos alunos como conseqüência do descaso do governo, que não investe em educação e saúde. Foi observado que as mesmas enfrentam a ausência de arborização, problemas com o lixo e entulhos dentro da própria escola, banheiros precários e que o solo vermelho da região dificulta o aspecto de limpeza das escolas. Também falta rede de esgoto doméstico e pluvial, e condições sanitárias adequadas.

\section{? Falta de recursos humanos na escola e desemprego na comunidade}

A escola não conta com o número necessário de funcionários, e para resolver este problema, ela aceita a oferta de trabalho "voluntário" de pessoas da comunidade, por exemplo, ajudando na confecção do lanche dos alunos. Por outro lado, essas pessoas se submetem a tal situação na expectativa da liberação de contratos provisórios de trabalho pelo Município, visando uma remuneração.

\section{? $\quad$ Problemas com o acondicionamento do lixo}

Apesar de algumas escolas terem recebido recipientes para a coleta seletiva do lixo, o caminhão responsável por essa coleta não chega em algumas escolas, que precisam transportar o lixo até o caminhão. Nas escolas onde o caminhão chega, ele o faz apenas uma vez por semana. O lixo acondicionado na escola por longo tempo, gera problemas como a presença de vetores, mal cheiro e aspecto visual desagradável.

\section{? $\quad$ Falta de material didático}

Os alunos perceberam que o desenvolvimento de ações pedagógicas algumas vezes esbarra na falta de material didático e subsídios teóricos. Perceberam assim a dificuldade que os professores tinham em dar continuidade ao projeto dentro da escola, mesmo considerando-o de grande relevância. Tentaram amenizar o 
problema, selecionando e encaminhando textos sobre o tema para os professores, mas sentiram que essa ação era pequena diante da carência das escolas.

\section{? À fome}

Um dos aspectos que causaram maior perplexidade dos alunos foram as atitudes das crianças em relação à alimentação. Isso pode ser percebido no seguinte relato:

"Ficamos muito tristes ao perceber o que estava acontecendo. Chovia por isso tinha muita lama vermelha, a escola era pequenininha e tinha muitos alunos.... A diretora conseguiu tomates maduros para a escola. Enquanto as caixas de tomates eram descidas do caminhão, os alunos avançavam, e comiam os tomates até sem lavar. Pareciam famintos"

Outro fato que reforçou o sentimento de perplexidade dos alunos foi o de presenciarem uma briga das crianças pelo lanche escola, uma querendo tomar o lanche da outra.

\section{? Moradias em área de risco e degradação de recursos hídricos}

Na reserva ambiental da região está situado um córrego com fluxo do d'agua muito pequeno devido ao assoreamento provocado pela construção de barracos quase dentro do córrego, com o desmatamento da mata ciliar. Além disso o esgoto dos barracos é despejado diretamente no corpo d'água e às suas margens, é lançado muito lixo.

\section{? O desmatamento}

Os alunos, demonstraram perceber a complexidade das relações entre as condições econômicas e ambientais, pois, apesar de não aprovarem, puderam entender os motivos que levam os moradores a desmatarem a reserva ambiental. Perceberam que, além da necessidade de moradias, para os moradores a reserva é considerada uma "vilã", já que se tornou um abrigo para marginais, um lugar de violência e perigo, que serve de referência para o tráfico de drogas, despejo de objetos roubados e assaltos. Logo, além de ignorar a ilegalidade e as conseqüências do desmatamento de uma reserva, os moradores acreditam que a melhor solução é a retirada total da mata para evitar os problemas que ela abriga.

\section{Problemas com a falta de higiene}

Os alunos perceberam que a falta de higiene das crianças, percebida nas escolas da região, muitas vezes é condicionada pelas condições de vida da população. Nesse sentido, relatam sobre a fala de uma diretora a respeito dessa questão: 
"A diretora falou que a questão da higiene dos alunos é problemática e citou o exemplo de um menino que sempre vai sujo para a escola e que ás vezes é preciso que a coordenadora lhe dê banho. Isto acontece porque ele não tem mãe, vive com a avó que trabalha fora, e ele passa a manhã inteira brincando na rua, esquece da hora, quando lembra, já está atrasado, chega descalço, sujo, com fome na escola e sem fazer as tarefas."

\section{CONCLUSÃO}

Pelos aspectos levantados nos relatos dos alunos, nota-se que o contato com a realidade e o desenvolvimento do trabalho de Educação Ambiental, contribuiu para a (re)construção de conhecimentos, possibilitando a criação de novos valores diante da relação ser humano/ambiente.

Segundo Saviani (1986) ${ }^{9}$, esse processo permite ao educando sair de uma visão sincrética (caótica) da totalidade da realidade vivenciada, para uma visão sintética (totalidade elaborada) pela mediação da análise. Esse método que pode tanto servir ao processo científico quanto ao processo de ensino estará consubstanciado na concepção dialética.

Os alunos, ao conhecer uma realidade onde se percebe um mundo diferente do seu em que se evidenciam problemas ambientais, suas relações com os diversos elementos sociais, políticos e econômicos, onde se evidencia, a pobreza, a fome, a falta de segurança e as diferenças de classe, sentiram que mesmo considerando pouco o que fizeram diante da realidade da Região Noroeste, perceberam-se eles próprios modificados.

Sabemos das limitações dos resultados do trabalho de Educação Ambiental para os alunos das escolas da Região Noroeste. Por outro lado, a partir da percepção da transformação das concepções de ambiente dos alunos universitários, é possível dizer que os objetivos do trabalho foram alcançados. Acreditamos que com alterações adequadas ele poderá ser repetido com sucesso, construindo uma práxis em Educação Ambiental, que leve em consideração as condições de vida das comunidades e os vários elementos que as constituem.

A Universidade Federal de Goiás - UFG, juntamente com os órgãos relacionados ao Meio Ambiente e à Educação, poderiam estar elaborando, em parceria, um plano de ação, com a participação das comunidades, na perspectiva de solucionar ou, pelo menos, amenizar os problemas ambientais existentes. 


\section{BIBLIOGRÁFICAS}

1. BARRETO, E. S. et. alii. Os currículos do Ensino Fundamental para as escolas brasileiras. São Paulo: Autores Associados/FCC, 1998. (Coleção Formação de Professores).

2. GUIMARÃES, Mauro. A dimensão ambiental na educação. Campinas, SP: Papirus, 1995 (coleção Magistério: Formação e Trabalho Pedagógico).

3. KOFF, E. D. ; LIPOVETSKY, N. Educação Ambiental e o Ensino de Ciências: alguns pontos. Goiânia: Secretaria Municipal de Educação, 1996. p. 16.

4. MEC. Secretaria de Educação Formal. Parâmetros Curriculares Nacionais. V. 9, Meio Ambiente e Saúde, Brasília: 1997.

5. MEC/SEMAM/IBAMA. Educação Ambiental: Projeto de divulgação de informações sobre educação ambiental. Brasília: 1991.

6. OKUDA, M. Y. et alii. Programa Curricular Mínimo para o Ensino para o Ensino Fundamental : Ciências $-1^{\text {a }}$. a $8^{\mathrm{a}}$. séries. Goiânia: Secretaria de Estado da Educação de Goiás, 1990.

7. PMSP. Secretaria Municipal de Educação - DOT. Estudos do meio e outras saídas para o ensino noturno: teoria e prática. Cadernos de formação, Série: Construindo a educação do jovem e adulto trabalhador. São Paulo: DOT/EDA 1992.

8. RADESPIEL, M. Temas Transversais: Oficina 1. Meio Ambiente, 1998. p.24-25.

9. SAVIANI, Demerval. Escola e Democracia. 11 ed. São Paulo: Cortez, 1986. 